\title{
Dendritic Cells Are Central Coordinators of the Host Immune Response to Staphylococcus aureus Bloodstream Infection
}

\author{
Daniela Schindler, ${ }^{*}$ Maximiliano G. Gutierrez, ${ }^{\dagger}$ \\ Andreas Beineke, ${ }^{\ddagger}$ Yvonne Rauter, $\$$ \\ Manfred Rohde," Simon Foster," \\ Oliver Goldmann, * and Eva Medina* \\ From the Infection Immunology Research Group," the Phagosome \\ Biology Research Group, ${ }^{\dagger}$ System-Orientated Immunology and \\ Infection Research, ${ }^{\S}$ and the Department of Medical \\ Microbiology, "I Helmboltz Centre for Infection Research, \\ Germany; the Institute of Pathology, ${ }^{*}$ University of Veterinary \\ Medicine Hanover, Hanover, Germany; and the Department of \\ Molecular Biology and Biotechnology," University of Sheffield, \\ Sheffield, United Kingdom
}

Dendritic cells (DCs) play an important role in integration of the immune responses induced by pathogens. The purpose of this study was to determine the importance of DCs in host defense against Stapbylococcus aureus bacteremia. Using a murine infection model, we demonstrated that DCs are rapidly recruited into infected tissue after intravenous inoculation with $S$. aureus. The recruited DCs were fully functional and in a more advanced stage of maturation than those isolated from uninfected mice. Depletion of DCs in CD11c-DTR transgenic mice resulted in substantial worsening of infection, as indicated by increased bacterial loads in kidneys and lungs, accelerated mortality, and more severe pathology. Furthermore, DC depletion completely abolished IL-12 production in response to infection. The beneficial effect afforded by DCs during $S$. aureus infection was not mediated by their contribution to direct bacterial killing, nor by increased neutrophil recruitment. Instead, neutrophil influx (along with expression of CXC chemokines) was significantly enhanced in infected tissue after depletion of DCs. We also found that the bactericidal capacity of the recruited neutrophils was significantly impaired in DC-depleted mice. More importantly, the detrimental effect of DC depletion was practically reversed by treatment with exogenous recombinant mouse IL-12. Our results demonstrated that DCs, probably through their production of IL-12, play an important role in coordinating the inflammatory response during $S$. aureus infection. (Am J Patbol 2012, 181:1327-1337; bttp://dx.doi.org/10.1016/j.ajpath.2012.06.039)

Bloodstream infection (bacteremia) is a major cause of morbidity and mortality and places substantial cost burdens on health care systems. ${ }^{1}$ Staphylococcus aureus is the most frequent cause of bacteremia worldwide. ${ }^{2}$ After entering the bloodstream, S. aureus can disseminate and establish infection in almost any organ. Consequently, staphylococcal bacteremia is often associated with serious metastatic complications, including infective endocarditis, osteomyelitis, and severe sepsis. ${ }^{3}$ The growing prevalence of antibiotic-resistant strains such as methicillin resistant $S$. aureus (MRSA), added to the increased use of implantable devices and the increase in the number of patients with immunocompromised status because of HIV infection or immunosuppression after transplantation or cancer treatment, has led to a significant increase in the incidence of $S$. aureus bacteremia over recent decades. ${ }^{4-6}$ Furthermore, the rampant prevalence of MRSA bacteremia increases the risk of inappropriate initial antimicrobial therapy, which in turn leads to treatment failures, longer hospitalizations, and greater mortality. ${ }^{7}$ New therapeutic options with novel modes of action that bypass the development of resistance are required to more effectively address the problems posed by $S$. aureus bloodstream infections. In this regard, therapeutic approaches aimed at enhancing the efficiency of the host immune response in eliminating $S$. aureus infection may represent the

Supported in part by the Federal Ministry of Education and Research joint project Susceptibility to Infections: SkinStaph [Bundesministerium für Bildung und Forschung-BMBF "Suszeptibilität bei Infektionen: SkinStaph" (FKZ 01KI1009B)]. M.G.G. is supported by a Helmholtz Young Investigator grant (Initiative and Networking funds of the Helmholtz Association).

Accepted for publication June 14, 2012.

Supplemental material for this article can be found at http://ajp. amjpathol.org or at http://dx.doi.org/10.1016/j.ajpath.2012.06.039.

Address reprint requests to Eva Medina, Ph.D., Infection Immunology Research Group, Helmholtz Centre for Infection Research, Inhoffenstraße 7, 38124 Braunschweig, Germany. E-mail: eva.medina@helmholtz-hzi.de. 
best option. However, to understand how the immune system can be manipulated to achieve a more efficient control of infection, we first need to obtain a more precise knowledge of the immune mechanisms involved in host defense against $S$. aureus bloodstream infection.

Dendritic cells (DCs) are sentinels of the immune system that play a crucial role in protecting the host against pathogens. ${ }^{8-11}$ Present in an immature state in peripheral tissue, on encounter with invading pathogens the DCs migrate into secondary lymphoid organs, where they initiate the primary immune response. During the migration process, DCs undergo maturation characterized by the up-regulation of $\mathrm{MHC}$ and costimulatory molecules such as CD86, CD80, and CD40 that are required for antigenspecific T-cell activation. ${ }^{11}$ In addition to their roles in the initiation of the acquired immune response, DCs release a number of cytokines and chemokines that activate cells of the innate immune system. ${ }^{11}$ The contribution of DCs to the host innate immune defense has been exemplified by the dramatic increase in mortality observed after depletion of DCs in mice affected by multimicrobial sepsis induced by cecal ligation and puncture. ${ }^{12}$ DCs are also required for an efficient control of human T-cell leukemia virus type 1 during the early stages of viral infection, ${ }^{13}$ as well as for limiting Streptococcus pyogenes dissemination in an experimental murine model of skin infection. ${ }^{14}$ Furthermore, several studies have demonstrated the beneficial effect of increasing the number of DCs for the treatment of infections. Thus, increased DC numbers after administration of Fms-related tyrosine kinase 3 ligand (FIt3L) improved bacterial clearance in a thermal injury mouse model of sepsis. ${ }^{15}$ Likewise, intrapulmonary transfer of DCs prevented fatal Aspergillus fumigatus infection in postseptic mice. ${ }^{16}$ Taken together, these observations support the potential of DC-targeting therapies for the treatment of infections.

In the present study, we used transgenic CD11c-DTR mice, which allow selective depletion of DCs in vivo, ${ }^{17}$ to examine the role of DCs in the host response to $S$. aureus bloodstream infection. Our results demonstrate that DCs are important regulators of the innate immune response to S. aureus bacteremia and are of benefit to the host. These data may be of use in future studies for the development of new strategies for the treatment of $S$. aureus bacteremia.

\section{Materials and Methods}

\section{Bacteria}

The bacteria used were S. aureus strain SH1000 wild-type and its derivative expressing GFP. ${ }^{18}$ Bacteria were grown to the mid-log phase at $37^{\circ} \mathrm{C}$ with shaking (150 rpm) in brain-heart infusion (BHI) medium (Carl Roth, Karlsruhe, Germany), collected by centrifugation for 10 minutes at $4000 \mathrm{rpm}(3200 \times \mathrm{g})$, and washed twice with sterile PBS. For the inoculum preparation, the bacterial suspension was diluted with PBS to the required concentration, and the number of viable bacteria was determined after serial diluting and plating onto agar containing 5\% sheep blood (Life Technologies-Invitrogen, Karlsruhe, Germany).

\section{Mice}

BALB/c mice were purchased from Harlan-Winkelmann (Borchen, Germany), B6.FVB-Tg [Itgax-DTR/GFP] 57Lan/J (referred to here as CD11c-DTR) transgenic mice ${ }^{17}$ were obtained from Steffen Jung (Weizmann Institute of Science, Rehovot, Israel). All experiments were approved by the local ethical board [Lower Saxony State Office for Consumer Protection and Food Safety (Niedersächsisches Landesamt für Verbraucherschutz und Lebensmittelsicherheit), Oldenburg in Germany]. Mice were inoculated with $4 \times 10^{7} \mathrm{CFU}$ of $\mathrm{S}$. aureus bacteria in $150 \mu \mathrm{L}$ of PBS via a lateral tail vein.

For depletion of DCs, CD11c-DTR transgenic mice were injected intraperitoneally with $4 \mathrm{ng} / \mathrm{g}$ body weight of diphtheria toxin from Corynebacterium diphtheriae (DT; Sigma-Aldrich, Deisenhofen, Germany) 24 hours before infection. This resulted in approximately $90 \%$ depletion of DCs (see Supplemental Figure S1 at $h$ ttp://ajp.amjpathol. org). DC depletion led to a threefold increase in the frequency of neutrophils in the spleen (see Supplemental Figure S2 at $h$ ttp://ajp.amjpathol.org). Other cell populations (including macrophages, B cells, and $\mathrm{CD}^{+}$or $\mathrm{CD}^{+} \mathrm{T}$ cells) were not affected by DC depletion (see Supplemental Figure S2 at $h$ ttp://ajp.amjpathol.org).

\section{Isolation of Spleen and Lungs DCs}

Single cell suspensions of spleens were prepared by passage through nylon mesh cell strainers. Lungs were minced with a scalpel and enzymatically digested with collagenase F and DNase (Qiagen, Hilden, Germany) for 30 minutes at $37^{\circ} \mathrm{C}$. Red blood cells were lysed with an ammonium chloride solution and the percentage of

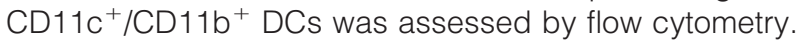
Calculation of absolute numbers of DCs was performed by multiplying the total cell count by the percentage of $\mathrm{CD}_{11 \mathrm{c}^{+} / \mathrm{CD} 11 \mathrm{~b}^{+} \text {cells }}$

For evaluation of the functional status of DCs during in vivo infection, DCs were purified from the spleen of mice before infection and at 24 and 48 hours after S. aureus inoculation, using anti-CD11c magnetic beads and positive selection columns according to the manufacturer's instructions ( $\mathrm{MS}^{+}$; Miltenyi Biotec, Bergisch Gladbach, Germany). The purity of the positive fraction was generally $>90 \%$. Purified DCs were ex vivo restimulated for 16 hours with $10^{7}$ cells of heat-killed $S$. aureus bacteria or with $1 \mu \mathrm{mol} / \mathrm{L} \mathrm{CpG}$; the supernatant was collected and used to determine the concentration of IL-6, TNF- $\alpha$, and IL-12.

\section{Maturation Status of DCs during in Vivo Infection}

Spleen cells were isolated from uninfected or $S$. aureusinfected BALB/c mice at 24 and 48 hours after bacterial inoculation and then stained with antibodies against $\mathrm{CD} 11 \mathrm{c}$ in combination with antibodies against CD40, CD80, CD86, or MHC class II (Pharmingen; BD Biosciences, Heidelberg, Germany) and subjected to flow cytometry analysis. Maturation of DCs was assessed by determining the geometric mean fluorescent intensity 
(Geo MFI) of surface CD40, CD80, CD86, and MHC class II expressed on the CD11 $\mathrm{c}^{+}$population.

\section{Assessment of Pathology}

Lungs, kidneys, livers, and hearts were isolated from S. aureus-infected DC-depleted and nondepleted CD11CDTR mice at 24 hours after bacterial inoculation and then were fixed in 10\% neutral formalin, processed, and embedded in paraffin. Sections (4 to $5 \mu \mathrm{m}$ thick) were prepared and stained with H\&E. The slides were examined by a pathologist (A.B.) who was blinded to the study groups. Histopathological lesions were graded for severity on a scale of 0 to 3 , as follows: 0 , nonpathological signs; 1 , multifocal neutrophilic interstitial pneumonia, focal purulent necrotizing myocarditis or focal nephritis; 2, focal purulent abscess myocarditis, multifocal necrotizing hepatitis, focal purulent epicarditis, focal neutrophilic myocarditis; and 3, multifocal purulent necrotizing hepatitis.

\section{Cytokine Determination}

Cytokine levels were determined in serum, lung homogenate, and supernatant of ex vivo restimulated splenic DCs by enzyme-linked immunosorbent assay according to the manufacturer's recommendations (BD Biosciences, San Diego, CA), using matched antibody pairs and recombinant cytokines as standards.

\section{Flow Cytometry}

Cells were incubated with purified rat anti-mouse CD16/ CD32 (BD Biosciences) for 5 minutes to block Fc receptors and then were stained with the specific antibodies or antibody combination for 30 minutes at $4^{\circ} \mathrm{C}$. Labeled cells were analyzed by flow cytometry in a FACSCalibur system (BD Biosciences).

\section{Generation of Bone Marrow-Derived DCs}

To generate bone marrow-derived DCs, bone marrow cells were flushed from murine femurs and tibias. Progenitor cells $\left(10^{6} / \mathrm{mL}\right)$ were resuspended and plated in RPMI 1640 (GIBCO, Paisley, UK) containing $10 \mathrm{ng} / \mathrm{mL}$ of recombinant mouse GM-CSF and $2 \mathrm{ng} / \mathrm{mL}$ of $\mathrm{IL}-4$ (R\&D Systems, Minneapolis, MN). DCs were cultured for 6 days at $37^{\circ} \mathrm{C}$ in $5 \% \mathrm{CO}_{2}$ and were gently washed and fed with fresh medium supplemented with GM-CSF (10 ng/mL) and IL-4 (2 ng/mL) on days 2 and 4 . On day 6 , the DC fraction was enriched using an OptiPrep (Axis-Shield, Oslo, Norway) density gradient medium. In terms of purity, the resulting cell population was $>80 \%$ DCs $\left(\mathrm{CD}_{11 \mathrm{C}^{+}}\right)$.

\section{Adoptive Transfer of DCs}

Bone marrow-derived DCs from BALB/c mice were differentiated as described above, and $10^{6}$ immature or LPS-matured DCs were intravenously inoculated into S. aureus-infected BALB/C or DC-depleted CD11c-DTR mice 16 hours after bacterial inoculation.

\section{In Vitro Infection of DCs}

Bone marrow-derived DCs were plated in 48-well plates at a density of $5 \times 10^{6} / \mathrm{mL}$ and infected with $S$. aureus at a multiplicity of infection (MOI) of 0.1 bacteria per DC for intracellular killing experiments or 20 bacteria per DC for living imaging, indirect immunofluorescence and electron microscopy examination and incubated for 2 hours in antibiotic-free medium. After incubation, infected DCs were washed twice with PBS to remove unbound bacteria, and further incubated in Dulbecco's modified Eagle's medium (DMEM; Gibco; Life Technologies-Invitrogen) supplemented with $10 \%$ FCS and $100 \mu \mathrm{g} / \mathrm{mL}$ gentamicin. For determination of intracellular killing, DCs were collected by centrifugation at 2, 6, and 24 hours after gentamicin treatment, washed with PBS, disrupted with distilled water, and plated in blood agar to quantify the number of viable intracellular bacteria. Alternatively, bacteria were collected at 24 hours after gentamicin treatment and processed for electron microscopy examination.

\section{Indirect Immunofluorescence}

DCs were seeded on sterile coverslips and exposed to GFP-S. aureus bacteria (MOI 20:1) for 4 hours. Coverslips were then rinsed to remove nonadherent cells; adherent cells were fixed with $4 \%$ paraformaldehyde. Infected DCs were then permeabilized by treatment with $0.025 \%$ Triton $\mathrm{X}-100$ in PBS for 5 minutes and incubated with rabbit anti-mouse LAMP-1 antibodies (BD Biosciences), followed by Alexa Fluor 546-conjugated goat anti-rabbit antibodies (Sigma-Aldrich). Acquisition of fluorescence images was performed using a Zeiss Axiophot microscope (Carl Zeiss, Oberkochen, Germany).

\section{Transmission Electron Microscopy}

Samples were fixed in cacodylate buffer $(0.1 \mathrm{~mol} / \mathrm{L}$ cacodylate, $0.01 \mathrm{~mol} / \mathrm{L} \mathrm{CaCl}$, $0.01 \mathrm{~mol} / \mathrm{L} \mathrm{MgCl}_{2}, 0.09 \mathrm{~mol} / \mathrm{L}$ sucrose, $\mathrm{pH} 6.9$ ) containing $2 \%$ glutaraldehyde and $5 \%$ formaldehyde for 30 minutes, washed with cacodylate buffer, and further fixed in a solution of $1.5 \%$ ferrocyanide and $1 \%$ osmium tetroxide in distilled water for 30 minutes at room temperature. Samples were then centrifuged, resuspended in a 1\% thiocarbohydrazide solution for 5 minutes, and again centrifuged; the pellet was resuspended in $1.5 \%$ ferrocyanide and $1 \%$ osmium tetroxide for 5 minutes and washed twice with cacodylate buffer. After immobilization of the samples in $2 \%$ agar, small cubes ( $2 \mathrm{~mm}$ on a side) were cut, dehydrated with a graded series of acetone, and embedded in Spurr's epoxy resin. Ultrathin sections were cut with a diamond knife, picked up with butvar-coated grids, counterstained with uranyl acetate and lead citrate, and examined under a Zeiss TEM910 transmission electron microscope at an acceleration voltage of $80 \mathrm{kV}$. Images were recorded digitally at calibrated magnifications using a Slow-Scan CCD camera (1024 × 1024 pixels; ProScan, Scheuring, Germany) with iTEM-Software version iTEM Build 1210 (Olympus Soft Imaging Solutions, Münster, Germany). 


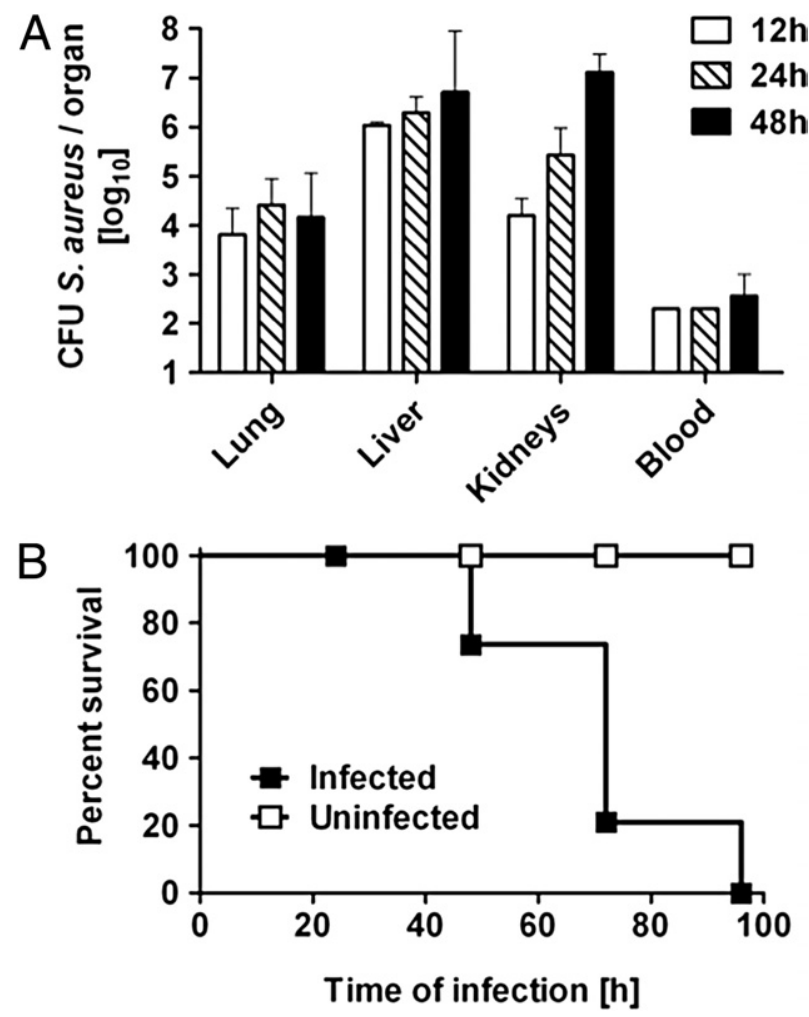

Figure 1. Course of $S$. aureus infection in BALB/c mice. A: Bacterial loads in the organs of $\mathrm{BALB} / \mathrm{C}$ mice at 12,24 , and 48 hours after intravenous inoculation with $S$. aureus. B: Survival curves of BALB/c mice, either uninfected or after intravenous infection with $S$. aureus. Data are expressed as means \pm SD (A) and represent one of three independent experiments with similar results (A and $\mathbf{B}$ ). $n=5$ mice per time point.

Contrast and brightness were adjusted using Adobe Photoshop CS4 (San Jose, CA).

\section{Live-Cell Imaging}

For live-cell imaging, $10^{6}$ DCs were seeded on 35-mm glass-bottom dishes (MatTek, Ashland, MA) in DMEM supplemented with $10 \%$ FCS, washed with PBS, and subsequently maintained in imaging medium (DMEM without Phenol Red, supplemented with 10\% FCS, pH 7.4, $2 \mathrm{mmol} / \mathrm{L}$ L-glutamine). DCs were infected with GFP-S. aureus bacteria at a $\mathrm{MOI}$ of 20:1. In some experiments, a solution of LysoTracker Red (1:20,000; Life Technologies-Invitrogen) in imaging medium was added to label DC acidic compartments. After 10 minutes of incubation, imaging was started with a Leica SP5 AOBS confocal microscope (Leica Microsystems, Wetzlar, Germany) equipped with an environment control chamber [EMBL Enterprise Management Technology Transfer (EMBLEM), Heidelberg, Germany]. During live imaging, a single focal plane was monitored in time (xyt scanning mode) using a $63 \times / 1.4 \mathrm{HCX}$ PL APO oil objective, argon laser (488 $\mathrm{nm})$, and diode-pumped solid state (DPSS) laser $(561 \mathrm{~nm})$ with a scanner frequency $400 \mathrm{~Hz}$ and line averaging of 4 .

\section{Bacterial Viability within Neutrophils}

To determine the amount of viable $S$. aureus bacteria within neutrophils, $\mathrm{Gr}-1^{+}$cells were purified from the lungs of infected mice using magnetic beads (Miltenyi Biotec), treated with lysostaphin $(5 \mu \mathrm{g} / \mathrm{mL})$ (Sigma-Aldrich) for 15 minutes to eliminate extracellular bacteria, and then extensively washed to remove traces of antibiotic. Neutrophils were collected by centrifugation and disrupted after treatment with distilled water; the amount of viable intracellular bacteria was determined after serial plating onto blood agar.

\section{In Vivo Reconstitution of DC-Depleted CD11C-DTR Mice with rlL-12}

DC-depleted CD11c-DTR mice were injected intraperitoneally with $100 \mathrm{ng}$ of recombinant mouse IL-12 (rlL-12; BioLegend, San Diego, CA) 4 hours after S. aureus inoculation. Control mice received only PBS vehicle. Mice were sacrificed at 24 hours of infection, and bacterial loads were determined in systemic organs by means of organ homogenate and serial plating.

To determine the effect of $\mathrm{rlL}-12$ on the recruitment of neutrophils, the lungs were isolated from PBS- or rIL-12treated DC-depleted CD11c-DTR mice and digested with collagenase $\mathrm{F}$ and DNase (Qiagen) for 30 minutes at $37^{\circ} \mathrm{C}$. Red blood cells were lysed with an ammonium chloride solution, and the percentage of neutrophils $\left(\mathrm{CD} 11 \mathrm{~b}^{+} / \mathrm{Gr}-1^{+}\right)$was assessed by flow cytometry.
A

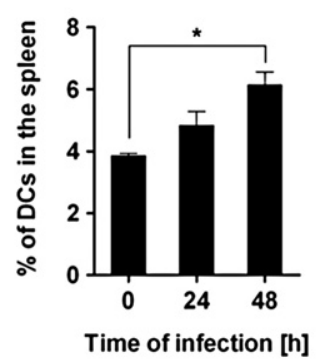

C

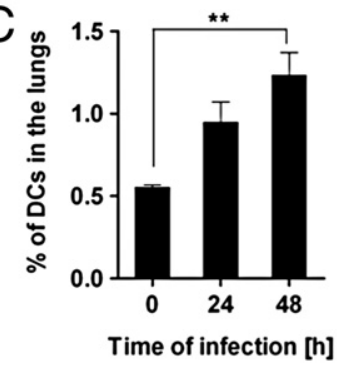

B

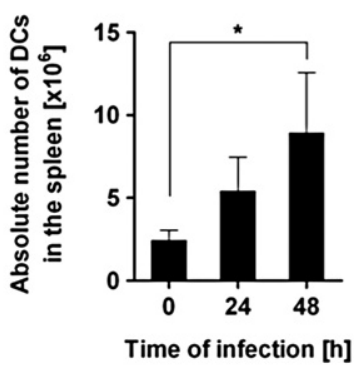

D

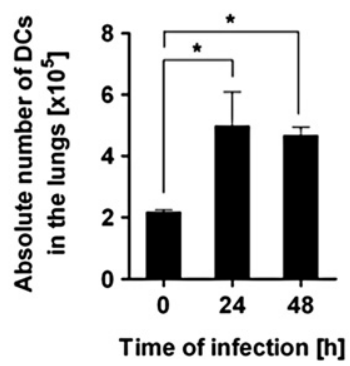

Figure 2. DCs are actively recruited into infected spleen and lung during the course of $S$. aureus bacteremia. A and B: Spleen. Percentage of DCs (A) and absolute number of DCs (B) present in the spleen of uninfected mice $(0$ hours) or $S$. aureus-infected mice at 24 and 48 hours after bacterial inoculation. C and D: Lungs. Percentage of DCs $(\mathbf{C})$ and absolute number of DCs (D) present in the lungs of uninfected mice (0 hours) or $S$. aureus-infected mice at 24 and 48 hours after bacterial inoculation. Data are expressed as means \pm $\mathrm{SD}$ and represent one of three independent experiments with similar results. ${ }^{*} P<0.05,{ }^{* * *} P<0.01 . n=5$ mice per time point. 


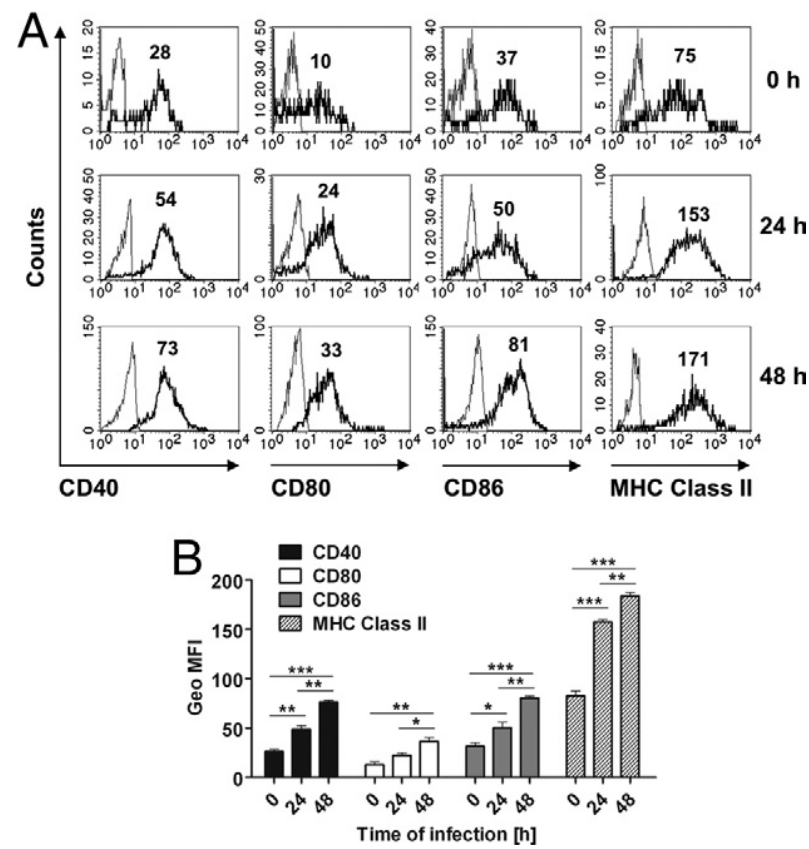

Figure 3. DCs recruited into the spleen of $S$. aureus-infected mice are in a more advanced maturation stage than splenic DCs from uninfected mice. A Single-parameter histograms show cell surface expression of the maturation markers CD40, CD80, CD86, and MHC class II on DCs isolated from the spleen of uninfected mice (0 hours) or $S$. aureus-infected mice at 24 and 48 hours after bacterial inoculation. Histograms depicting the fluorescence intensity of specifically stained cells (thick lines) are overlaid on histograms of cells incubated with the isotype control antibody (thin lines). The number within each panel indicates the geometric mean fluorescence intensity of the specific marker expressed by the DCs. B: Geometric mean fluorescent intensity (Geo MFI) of surface CD40, CD80, CD86, and MHC class II staining of the DCs in $\mathbf{A}$. Data are expressed as means \pm SD $(\mathbf{B})$ and represent one of three independent experiments with similar results $(\mathbf{A}$ and $\mathbf{B}) .{ }^{*} P<0.05,{ }^{* *} P<$ 0.01 , and ${ }^{* * * * *} P<0.001 . n=4$ mice per time point

\section{Statistical Analysis}

Data were analyzed using GraphPad Prism software version 4.0 (GraphPad Software, La Jolla, CA). Unless otherwise specified, data are expressed as means \pm $\mathrm{SD}$. Comparison between groups was performed by the use of two-tailed $t$-test or one-way analysis of variance. Comparison of survival time curves was performed by use of the logrank test. $P$ values of $\leq 0.05$ were considered significant.

\section{Results}

\section{Recruitment and Activation of DCs in Infected Tissue during S. aureus Bloodstream Infection}

The present study used a previously described murine model of $S$. aureus bloodstream infection. ${ }^{19}$ After intravenous inoculation into mice, $S$. aureus can establish metastatic infection in essentially all organs. The bacterial burdens over time in lungs, liver, kidneys, and blood after bacterial inoculation, along with the survival times of infected animals, are shown in Figure 1. With the progression of infection, spleens became enlarged (see Supplemental Figure S3A at http://ajp.amjpathol.org), and the total cell numbers increased significantly (see Supplemental Figure S3B at http://ajp.amjpathol.org). Both the percentage and the absolute number of DCs increased significantly in the spleen of infected mice as infection progressed (Figure 2, A and B). We next investigated whether the recruitment of DCs also took place in peripheral organs, such as the lungs. For this purpose, lungs were isolated from infected mice at 24 and 48 hours of infection and enzymatically digested; the number of lung DCs (CD11 $\left.\mathrm{c}^{\text {intermediate }} / \mathrm{CD} 11 \mathrm{~b}^{\text {high }}\right)$ determined by flow cytometry. Both the percentage and the absolute number of DCs increased significantly in the lungs of infected mice (Figure 2, C and D).

The recruited DCs were in a more advanced activation stage than DCs from uninfected mice, as shown by the gradual increase in expression of the maturation markers CD40, CD80, CD86, and MHC class II (Figure 3, A and B).
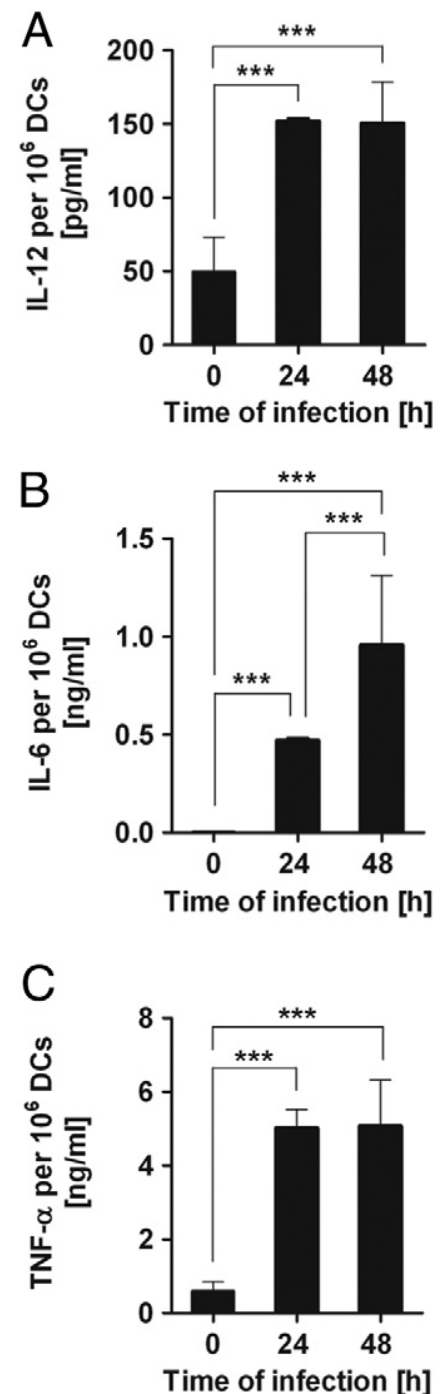

Figure 4. DCs become activated in vivo during $S$. aureus infection. Levels of IL-12 (A), IL-6 (B), and TNF- $\alpha(\mathbf{C})$ released by DCs purified from the spleen of uninfected mice (0 hours) or $S$. aureus-infected mice at 24 and 48 hours after intravenous bacterial inoculation and restimulated ex vivo with $10^{7}$ heat-killed $S$. aureus bacteria for 16 hours. Data are expressed as means \pm SD and represent one of three independent experiments with similar results. ${ }^{\text {*a*k }} P<0.001 . n=5$ mice per time point. 

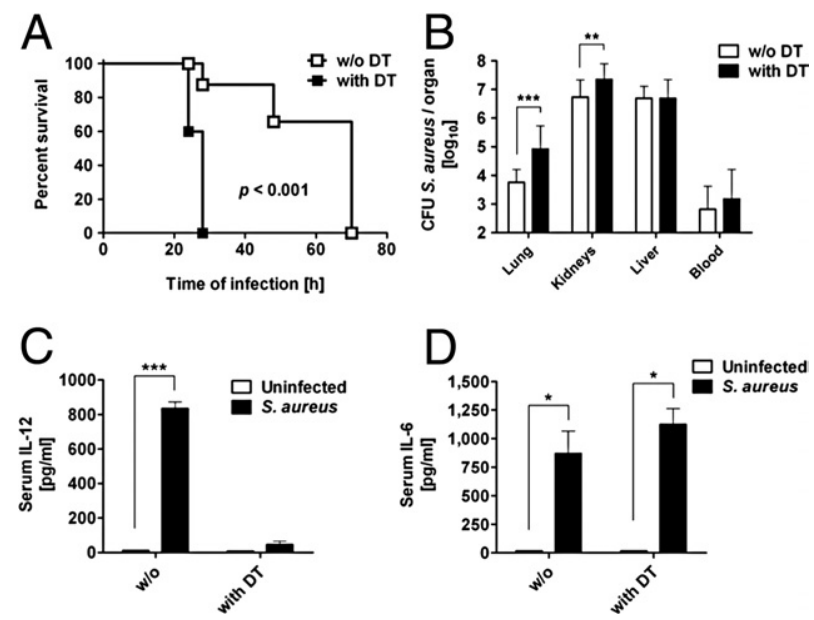

Figure 5. Depletion of DCs aggravates the severity of $S$. aureus bloodstream infection. CD11c-DTR transgenic mice were treated with DT to deplete DCs (with DT) or with PBS vehicle (w/O DT) as nondepleted control and then were infected intravenously with $S$. aureus bacteria. A: Survival curves of DC-depleted and nondepleted mice after intravenous inoculation with $S$. aureus bacteria. B: Bacterial loads in the lungs, kidneys, liver, and blood of DC-depleted and nondepleted mice at 24 hours after bacterial inoculation. C and D: Serum levels of IL-12 (C) and IL-6 (D) in DC-depleted and nondepleted mice before and 24 hours after $S$. aureus inoculation. Data are expressed as means \pm SD $(\mathbf{B}-\mathbf{D})$ and represent one of three independent experiments with similar results $(\mathbf{A}-\mathbf{D}) .{ }^{*} P<0.05,{ }^{* * *} P<0.01$, and ${ }^{\text {***** }} P<0.001 . n=5$ mice per group.

Furthermore, the DCs recruited within the spleen of infected mice were fully functional, as revealed by the significantly greater production of the cytokines IL-12, IL-6, and TNF- $\alpha$ after ex vivo stimulation with heat-killed $S$. aureus bacteria (Figure 4). Similar results were obtained after stimulation of splenic DCs with CpG DNA (data not shown).

\section{Depletion of DCs Exacerbates the Severity of S. aureus Infection}

To evaluate the relevance of DCs in host defense during S. aureus bacteremia, we used CD11c-DTR mice to selectively deplete DCs in vivo. ${ }^{17}$ These transgenic mice express the diphtheria toxin receptor on the CD11c promoter region, which allows for selective depletion of DCs after administration of DT. A single DT injection led to

Table 1. Scoring of Inflammatory Lesions in Organs of S. aureus-Infected Nondepleted and DC-Depleted Mice at 24 Hours after Bacterial Inoculation

\begin{tabular}{|c|c|c|c|c|c|c|c|c|}
\hline \multirow[b]{2}{*}{ Organ } & \multicolumn{4}{|c|}{$\begin{array}{l}\text { Nondepleted }(n / N) \text {, } \\
\text { by grade }\end{array}$} & \multicolumn{4}{|c|}{$\begin{array}{l}\text { DC-depleted }(n / N), \\
\text { by grade }\end{array}$} \\
\hline & 0 & 1 & 2 & 3 & 0 & 1 & 2 & 3 \\
\hline Heart & $1 / 3$ & $1 / 3$ & $1 / 3$ & $0 / 0$ & $0 / 3$ & $0 / 3$ & $3 / 3$ & $0 / 3$ \\
\hline Lungs & $2 / 3$ & 0/0 & $1 / 3$ & $0 / 3$ & $2 / 3$ & $1 / 3$ & $0 / 3$ & $0 / 3$ \\
\hline Liver & $0 / 3$ & $0 / 3$ & $3 / 3$ & $0 / 3$ & $0 / 3$ & $0 / 3$ & $2 / 3$ & $1 / 3$ \\
\hline Kidneys & $2 / 3$ & $1 / 3$ & $0 / 3$ & $0 / 3$ & $0 / 3$ & $3 / 3$ & $0 / 3$ & $0 / 3$ \\
\hline
\end{tabular}

Severity was graded on a scale of 0 to 3 , as follows: 0 , nonpathological signs; 1 , multifocal neutrophilic interstitial pneumonia, focal purulent necrotizing myocarditis or focal nephritis; 2 , focal purulent abscess myocarditis, multifocal necrotizing hepatitis, focal purulent epicarditis, focal neutrophilic myocarditis; and 3, multifocal purulent necrotizing hepatitis. $n=$ 3 mice per group.
A
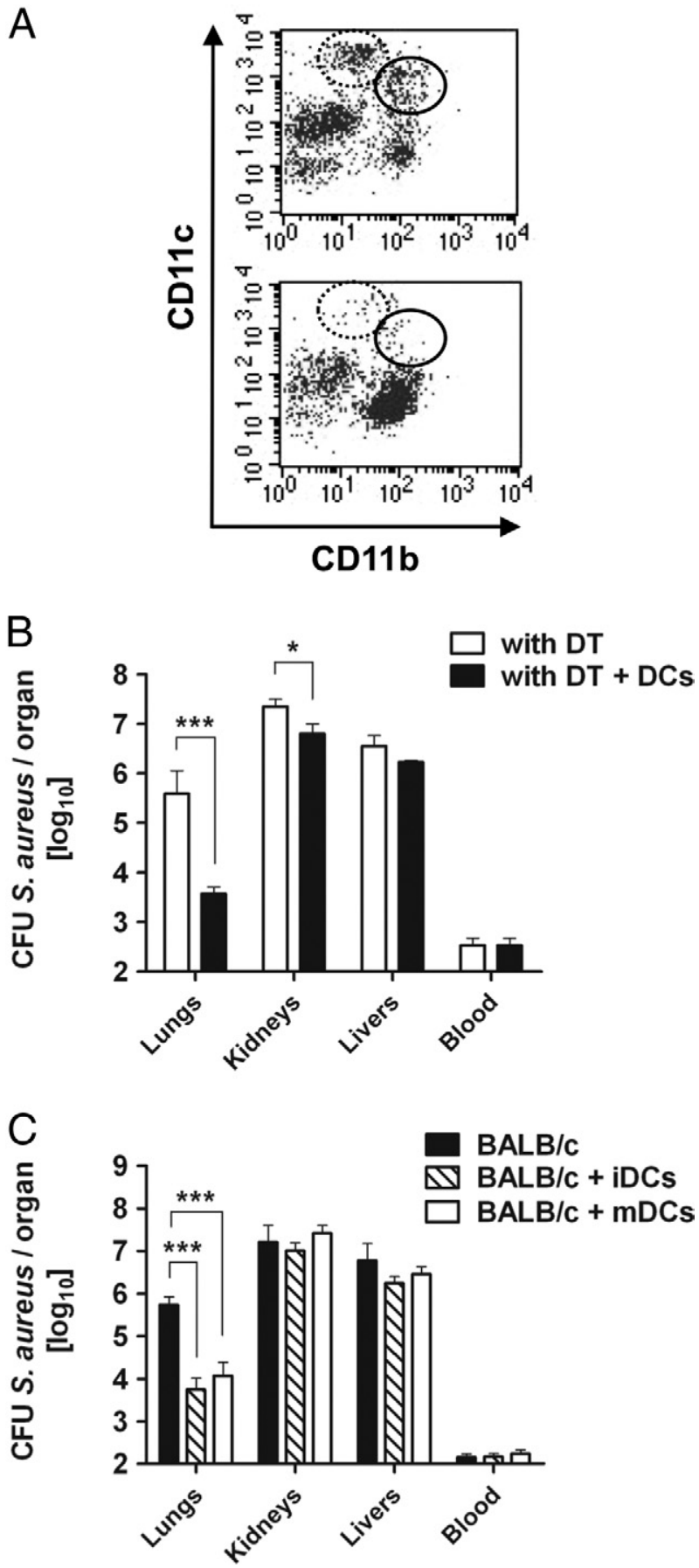

Figure 6. Exacerbation of infection in DT-treated CD11c-DTR mice is specifically attributed to the depletion of DCs. A: Flow cytometry analysis of lung cells obtained after enzymatic digestion of lung tissue from CD11c-DTR transgenic mice treated with either PBS vehicle (top panel) or DT to deplete DCs (bottom panel) at 24 hours after intravenous inoculation with $S$. aureus. Alveolar macrophages (dotted circle) and DCs (solid circle) were identified by their relative expression of CD11c and CD11b. B: Bacterial loads in the lungs, kidneys, liver, and blood of DC-depleted CD11C-DTR mice adoptively transferred with $10^{6}$ DCs obtained from BALB/C mice at 12 hours after $S$. aureus inoculation (with DT +DCs) or from untreated DT-depleted mice (with DT). CFUs were determined in the different organs at 24 hours after DC transfer. C: Bacterial loads in the lungs, kidneys, liver, and blood of $\mathrm{BALB} / \mathrm{c}$ mice after receiving either $10^{6}$ immature DCs (iDCs), $10^{6}$ LPS-matured DCs (mDCs), or PBS intravenously at 12 hours after bacterial inoculation. CFUs were determined in the different organs at 24 hours after DC transfer. Data are expressed as means \pm SD $(\mathbf{B}$ and $\mathbf{C})$ and represent one of three independent experiments with similar results $(\mathbf{A}-\mathbf{C}) .{ }^{*} P<0.05$, ${ }_{* * * * *} P<0.001$. $n=3$ mice per group. 

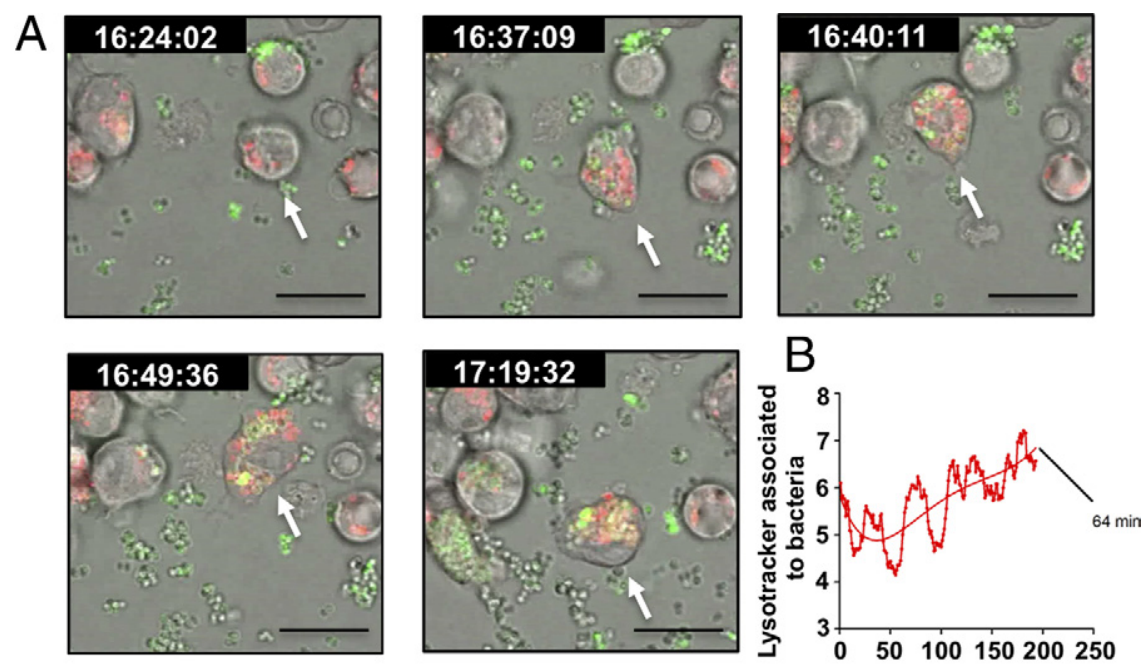

Frame number
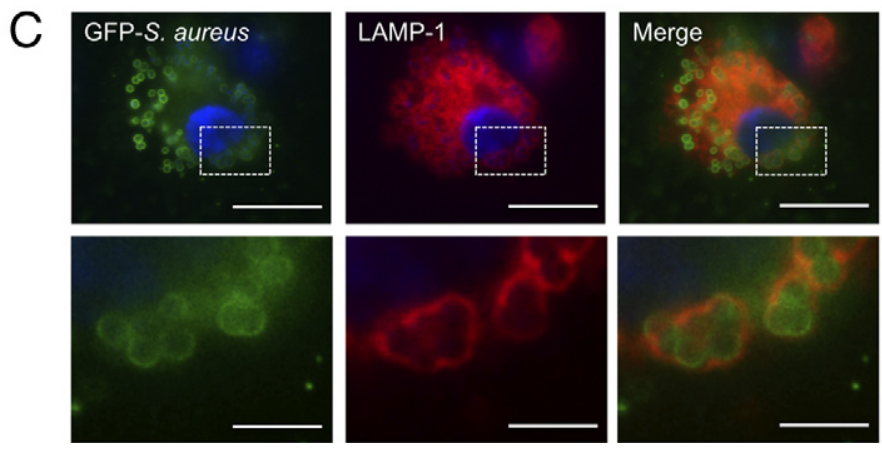

Figure 7. Phagocytic uptake of $S$. aureus by DCs. A: Representative frames from real-time video capture (see Supplemental Video S1 at http://ajp.amjpathol.org) showing phagocytosis of $S$. aureus bacteria by a DC (arrow). Bacteria are labeled with GFP (green); DCs are labeled with LysoTracker Red. After 1 hour of infection, most of the internalized bacteria were localized within acidic phagocytic vacuoles (yellow vacuoles in the last panel). B: Fluorescence profile of LysoTracker Red analyzed frame by frame during a period of 64 minutes using ImageJ software version 1.46a (NIH, Bethesda, MD). C: Confocal immunofluorescence sections of a DC infected with GFP-expressing $S$. aureus bacteria (green) for 4 hours, fixed, and stained for LAMP-1 (red) and DNA (blue). The boxed areas (top row) correspond to the higher-magnification images in the row below. Scale bars: $10 \mu \mathrm{m}$ (A; B, top row; $\mathbf{C}$, top row); $4 \mu \mathrm{m}(\mathbf{B}$, bottom row; C, bottom row).
$>90 \%$ elimination of DCs $\left(\mathrm{CD}_{11 \mathrm{C}^{+}}\right.$) (see Supplemental Figure $\mathrm{S} 1$ at $h$ ttp://ajp.amjpathol.org).

Depletion of DCs after treatment with DT resulted in accelerated mortality, and in significantly increased bacterial loads in the lungs and kidneys of infected CD11CDTR mice (Figure 5, A and B). In addition, DC-depleted mice exhibited higher levels of infection-associated pathology than nondepleted mice (Table 1; see also Supplemental Figure S4 at http://ajp.amjpathol.org). Furthermore, production of IL-12 in response to infection was completely abolished in DC-depleted mice (Figure 5C). In contrast, the infection-related production of IL-6 was not affected by the depletion of DCs (Figure 5D).

Because the lung was the organ more affected by the depletion of DCs, and because it has been reported that treatment of CD11c-DTR mice with DT can result in the depletion of alveolar macrophages in addition to DCs, ${ }^{20}$ we next investigated whether alveolar macrophages were also affected by DT treatment in our experimental system. We used CD11c and CD11b markers to differentiate alveolar macrophages (CD11chigh/CD11b low $)$

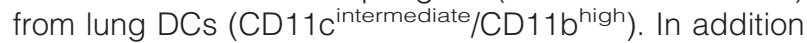
to depletion of lung DCs, treatment with DT induced extensive depletion of alveolar macrophages (Figure 6A). To determine whether the loss of DCs but not of alveolar macrophages was directly responsible for the exacerbation of infection, DC-depleted CD11c-DTR mice were adoptively transferred with bone marrow-derived DCs obtained from BALB/c mice. Intravenous injection of DCs 12 hours after bacterial inoculation restored the capacity of DC-depleted CD11c-DTR mice to control the infection in the lungs and kidneys to the levels observed in nondepleted mice (Figure 6B). These results clearly confirmed that the observed increased severity of infection in DT-treated CD11c-DTR mice was specifically attributable to the reduction of DCs. More importantly, we could show that adoptive transfer of either immature or LPS-matured DCs into normal BALB/mice improved the capacity of these animals to clear $S$. aureus bacteria in the lungs (Figure 6C).

Taken together, these results provide clear evidence for a protective role of DCs during $S$. aureus bacteremia.

\section{DCs Do Not Contribute to Direct Killing of S. aureus}

The next step was to investigate the immunological mechanisms underlying the beneficial effect afforded by DCs during S. aureus bloodstream infection. Because DCs are phagocytic cells, the ability of DCs to contribute to direct killing of $S$. aureus bacteria was evaluated. Livecell imaging microscopy was used to visualize the dynamic interactions between S. aureus and DCs. Bone marrow-derived DC acidic cellular compartments were stained with LysoTracker Red and then incubated with 
A
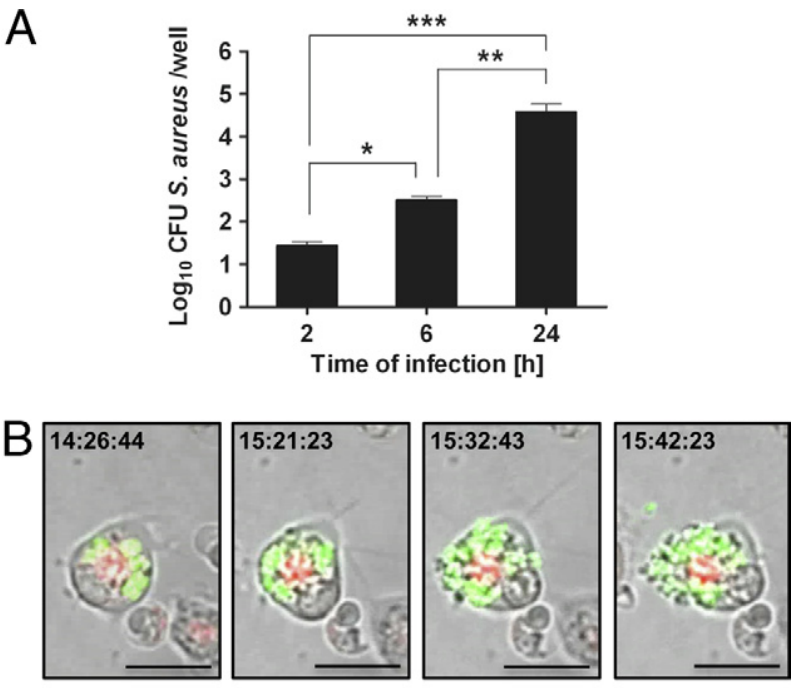

C

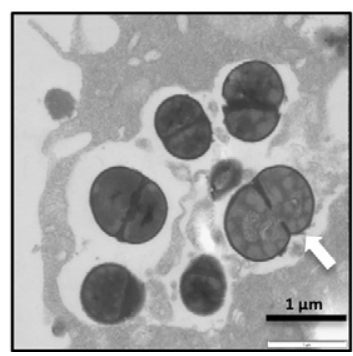

Figure 8. S. aureus bacteria survive, and even multiply within DCs. A Number of viable $S$. aureus bacteria within DCs at 2, 6, and 24 hours after in vitro infection. B: Representative frames from real-time video capture (see Supplemental Video S2 at http://ajp.amipathol.org) show GFP-S. aureus bacteria replicating within a DC; this photographic sequence covers approximately 1.2 hours. C: Transmission electron micrograph shows replicating intracellular $S$. aureus bacteria within a DC. Note bacterium undergoing active cell division (arrow). Data are expressed as means \pm SD and represent one of three independent experiments with similar results. ${ }^{*} P<0.05$, ${ }^{* *} P<0.01$, and ${ }^{* * * *} P<0.001$. Scale bars: $10 \mu \mathrm{m}(\mathbf{B}) ; 1 \mu \mathrm{m}(\mathbf{C}) . n=4$.

GFP-S. aureus bacteria at a $\mathrm{MOI}$ of 20 bacteria per DC. Selected frames of a representative video (see Supplemental Video S1 at $h$ ttp://ajp.amjpathol.org) are shown in Figure 7A. DCs began to internalize S. aureus bacteria at 30 minutes after coincubation and continued unceasing (Figure 7A). After 1 hour of infection, most of the internalized bacteria were localized within acidic phagocytic vacuoles (Figure 7A). The mean fluorescence intensity of the red fluorescence associated with GFP-S. aureus phagosomes over time was then quantified. The intensity of red fluorescence (LysoTracker) significantly increased during the first 64 minutes (Figure 7B), indicating a progressive acidification of the phagosomes within the infected DCs. Indeed, most staphylococci within DCs were confined within intracellular compartments that acquire the lysosome-associated membrane protein LAMP-1 (Figure 7C).

To determine the capacity of DCs to kill internalized S. aureus bacteria, DCs were infected with $S$. aureus at a $\mathrm{MOI}$ of 1 bacterium per $10 \mathrm{DCs}$, and the amount of viable intracellular bacteria was determined at progressive times of infection by plating. S. aureus bacteria were capable of surviving and even multiplying within the DCs (Figure 8A). These results were confirmed by live-cell imaging showing a rapid increase in the number of intracellular S. aureus bacteria (Figure 8B; see also Supplemental Video S2 at http://ajp.amjpathol.org). Consistent with this observation, profiles of bacteria in process of division were often observed by transmission electron microscopy (Figure 8C).

\section{Depletion of DCs Does Not Reduce the Recruitment of Neutrophils into the Site of Infection}

Because a contribution of DCs to direct bacterial killing was excluded, we next investigated whether the beneficial effect afforded by the DCs was due to their participation in the recruitment to the site of infection of inflammatory cells involved in bacterial clearance. Unexpectedly, the percentage of neutrophils recruited in response to infection was significantly higher in the lungs of DC-depleted mice than in the lungs of nondepleted mice (Figure 9A). Both the percentage and the absolute number of recruited neutro-
A

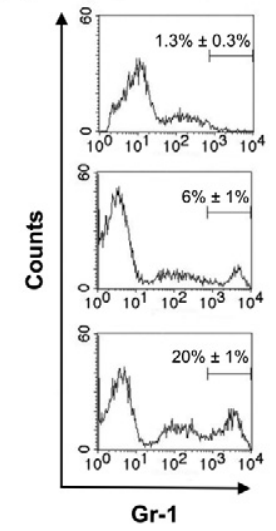

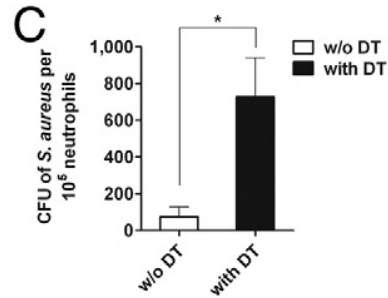

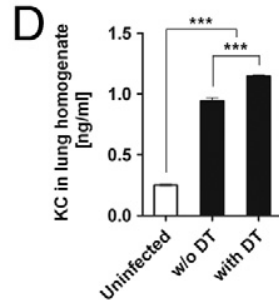

$\mathrm{E}$
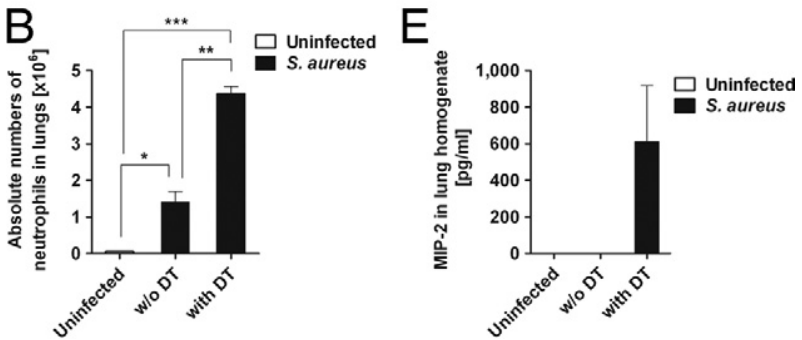

Figure 9. DC-depletion resulted in increased recruitment to the site of infection of neutrophils with decreased bactericidal capacity. A: Representative histograms are shown for expression of the neutrophil marker Gr-1 in the cell populations of lungs of uninfected mice (top panel), $S$. aureus-infected and PBS-treated CD11c-DTR mice (middle panel), and $S$. aureus-infected and DT-treated CD11c-DTR mice (bottom panel) at 24 hours after bacterial inoculation. B: Absolute number of neutrophils recruited into the lungs in the three groups of mice. C: Quantification of viable intracellular $S$. aureus bacteria per neutrophil in the lungs of $S$. aureus-infected DC-depleted (with DT) or nondepleted (w/O DT) CD11c-DTR mice at 24 hours after bacterial inoculation. D and E: Levels of KC (D) and MIP-2 (E) in lung homogenates of uninfected and $S$. aureus-infected mice in the presence (w/o DT) or absence (with DT) of DCs. The levels of KC and MIP-2 were determined in lung homogenates at 24 hours after bacterial inoculation. Data are expressed as means $\pm \mathrm{SD}(\mathbf{B}-\mathbf{E})$ and represent one of three independent experiments with similar results. ${ }^{*} P<0.05,{ }^{* *} P<0.01$, and ${ }^{* * * *} P<0.001 . n=5$ mice per group. 
phils were significantly higher in the lungs of DC-depleted mice (Figure 9B). More interestingly, the amount of viable $S$. aureus bacteria per neutrophil was significantly higher (10fold) in the neutrophils isolated from the lungs of DC-depleted than of nondepleted mice (Figure 9C). These observations indicate that neutrophils were less effective at killing ingested S. aureus bacteria when DCs were absent.

Because neutrophils are predominantly responsive to members of the CXC chemokine family, we then determined the levels of the chemokines MIP-2 and KC in the lungs of $S$. aureus-infected DC-depleted and nondepleted mice. The levels of both KC and MIP-2 were significantly greater in the lungs of DC-depleted mice (Figure 9, D and E).

\section{IL-12 Reconstitution Results in Improved Control of S. aureus Infection in DC-Depleted CD11C-DTR Mice}

Because the production of IL-12 in response to $S$. aureus infection was completely abolished after DC depletion (Figure 5C), we speculated that a breakdown in IL-12 production could contribute, at least in part, to the detrimental effect of DC depletion in the course of $S$. aureus bloodstream infection. To test this hypothesis, rIL-12 was administered to DC-depleted CD11C-DTR mice 4 hours after $S$. aureus inoculation, and the bacterial burdens in systemic organs were determined at 24 hours of infection. The rIL-12-reconstituted DC-depleted CD11c-DTR mice exhibited significantly lower bacterial loads in lungs and kidneys than the PBS-treated mice (Figure 10A). Furthermore, rIL-12-treated DC-depleted CD11c-DTR mice exhibited significantly lower amounts of neutrophils recruited into the lungs, compared with PBS-treated mice (Figure 10, B and C). These results clearly demonstrate the relevance of IL-12 production by DCs in the modulation of the inflammatory response during $S$. aureus infection.

\section{Discussion}

In the present study, we investigated the role of DCs in the host innate immune response to $S$. aureus bacteremia. Our results show that DCs are mobilized and actively recruited into infected tissue during the course of $S$. aureus infection. Adoptive transfer and depletion experiments demonstrated that DCs made a positive contribution to host defense during $S$. aureus bloodstream infection. Thus, we found that depletion of DCs resulted in substantial worsening of pathogen clearance, particularly in the lungs and kidneys, and in accelerated mortality of infected animals. In accord with our data, a recent study indicated that depletion of DCs in mice intranasally inoculated with S. aureus was associated with increased bacterial load in the lungs. ${ }^{21}$ We also demonstrated that transfer of DCs caused a significant enhancement in bacterial clearance in S. aureus-infected mice. Taken together, these results imply that DCs contribute to host defense during $S$. aureus bacteremia.

Next, we investigated the immunological mechanisms underlying the beneficial effect afforded by DCs during in
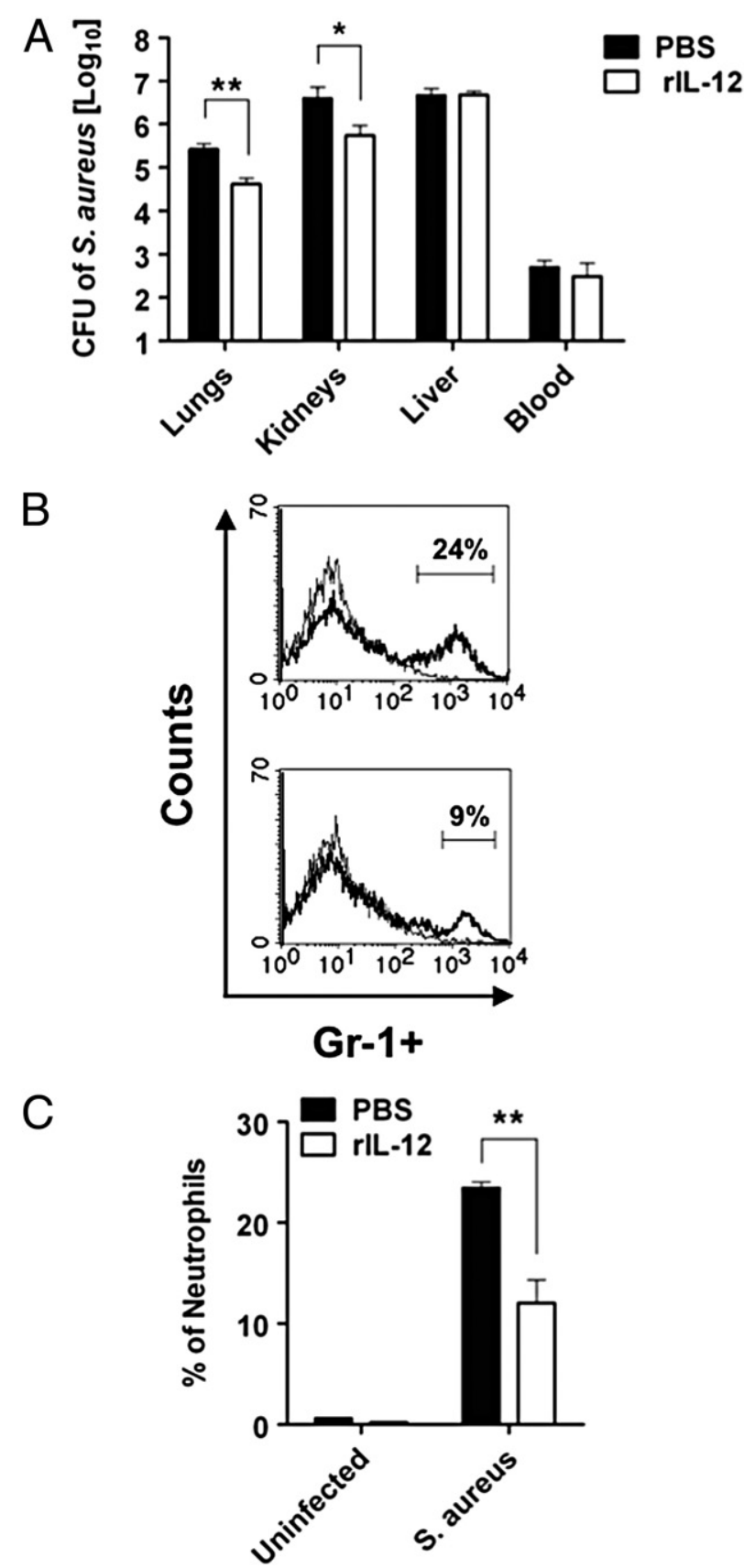

Figure 10. Administration of exogenous rIL-12 improves the resistance of DC-depleted CD11C-DTR mice to $S$. aureus infection. CD11C-DTR mice were treated with DT to deplete DCs; after 24 hours, the mice were intravenously infected with $S$. aureus bacteria. Infected DC-depleted mice were injected intraperitoneally with $100 \mathrm{ng}$ of rIL-12 or control PBS at 4 hours after bacterial inoculation. A: Bacterial loads in lungs, kidneys, liver, and blood of PBStreated or rIL-12-treated DC-depleted CD11c-DTR mice at 24 hours after bacterial inoculation. B: Representative histograms are shown for expression of the neutrophil marker Gr-1 in the cell populations of lungs of PBS-treated DC-depleted CD11c-DTR (top panel) or rIL-12-treated DC-depleted CD11cDTR (bottom panel) in uninfected control mice (thin line) and in $S$ aureus-infected mice ( 24 hours of infection; thick line). C: Percentage of neutrophils recruited into the lungs in the four groups of mice. Data are expressed as means $\pm \mathrm{SD}(\mathbf{A}$ and $\mathbf{C})$ and represent one of two independent experiments with similar results $(\mathbf{A}-\mathbf{C}) .{ }^{*} P<0.05,{ }^{* *} P<0.01 . n=8$.

vivo infection. Our results demonstrated that DCs did not play a major role in direct bacterial killing and that $S$. aureus bacteria survived and even multiplied within the DCs. Likewise, S. aureus has been shown to survive 
within other professional phagocytes, including human ${ }^{22}$ and murine neutrophil granulocytes, ${ }^{23}$ as well as human monocyte-derived macrophages. ${ }^{24}$ Within these cells, $S$. aureus can evade the lethal effect of the phagolysosome by producing oxygen free radical scavenger compounds, including catalases, ${ }^{25}$ staphyloxanthin, ${ }^{26}$ and yellow carotenoid pigments. ${ }^{27}$

We then hypothesized that DCs may indirectly contribute to bacterial killing through their participation in the recruitment to the site of infection of inflammatory cells involved in bacterial eradication. We focused on the neutrophil population, because neutrophils are key elements in the host innate immune response to $S$. aureus infection. ${ }^{19,28,29}$ Our data, however, revealed that the recruitment of neutrophils in infected tissue was increased rather than decreased in mice depleted of DCs. These findings demonstrate that exacerbation of $S$. aureus infection in DC-depleted mice was not attributable to a reduced recruitment of neutrophils and also suggested that increasing the number of neutrophils in infected organs is rather detrimental to the host. Despite their role in $S$. aureus clearance, there is now substantial evidence indicating that neutrophils recruited in large numbers during staphylococcal infection have a harmful effect. ${ }^{30}$ The destructive potential of an excessive amount of neutrophils might be due to the massive release of proteolytic enzymes and toxic compounds generated during neutrophil activation. Therefore, neutrophil entry into tissue must be tightly regulated in vivo to avoid damage to the host.

We also found that the increased neutrophil numbers in DC-depleted mice correlated with increase in bacterial counts, rather than with increased bacterial killing. Similar observations have been reported in murine models of $S$. aureus peritonitis ${ }^{23}$ and hind-paw infection. ${ }^{31}$ In addition, there is a wide body of clinical evidence showing a similar inverse relationship between neutrophil numbers and S. aureus bacteremia. Thus, comparison of bloodstream infections in neutropenic and non-neutropenic patients revealed $S$. aureus bacteremia to be significantly less frequent in neutropenic patients. ${ }^{32-34}$ More interesting was the observation that neutrophils isolated from the lungs of DC-depleted mice harbored significantly higher numbers of intracellular viable $S$. aureus bacteria than neutrophils isolated from nondepleted animals. This implies that the ability of the recruited neutrophils to kill ingested S. aureus bacteria was even poorer in the absence of DCs. In this regard, several studies provide evidence that local release of CXC chemokines promotes survival of $S$. aureus within neutrophils by facilitating bacterial internalization into an intracellular niche where they are protected from the killing mechanisms of the host. ${ }^{23,31}$ In accord, we found significantly higher levels of $\mathrm{KC}$ and MIP-2 in the lungs of $S$. aureus-infected, DC-depleted, mice than in S. aureus-infected, nondepleted mice. Therefore, it is likely that DCs are key elements for the maintenance of the fine balance between protective immune responses and inflammatory pathology during $S$. aureus infection.

An additional finding of the present study is that DCs are the major source of IL-12 during S. pyogenes infection, because their depletion resulted in complete abrogation of IL-12 production. IL-12 is an important immu- noregulatory cytokine with multiple biological functions that play a key role in protection against several bacterial and viral infections. ${ }^{35}$ There is now convincing evidence that IL-12 plays an important role in the immune response to $S$. aureus infection. Thus, IL-12 deficiency in humans has been associated with recurrent $S$. aureus infection. ${ }^{36}$ Furthermore, Hultgren et $\mathrm{al}^{37}$ reported that mice deficient in the production of IL-12 are much more susceptible to S. aureus infection than their wild-type counterparts. These investigators also demonstrated that the inferior capacity of IL-12-deficient mice to control S. aureus infection was not due to a direct effect of IL-12 in the phagocytosis or killing of $S$. aureus bacteria by phagocytic cells but rather an indirect effect via modulation of expression of other cytokines. ${ }^{37}$ In the present study, reconstitution with exogenous rlL-12 significantly improved the capacity of DC-depleted mice to control S. aureus infection, suggesting that the beneficial role afforded by DCs during S. aureus infection might be mediated, at least in part, by the production of IL-12.

In conclusion, our data provide compelling evidence that DCs are key coordinators of the immune response to S. aureus bloodstream infection. Increasing the number of DCs or enhancing their functional capacity could therefore constitute innovative therapeutic approaches to enhance the host resistance to $S$. aureus infection.

\section{Acknowledgments}

We thank Steffen Jung (Weizmann Institute of Science, Rehovot, Israel) for providing the B6.FVB-Tg [Itgax-DTR/ GFP] 57Lan/J transgenic mice and Ina Schleicher, Sabine Lehne, and Claudia Höltje for excellent technical assistance.

\section{References}

1. Kollef MH, Zilberberg MD, Shorr AF, Vo L, Schein J, Micek ST, Kim M Epidemiology, microbiology and outcomes of healthcare-associated and community-acquired bacteremia: a multicenter cohort study. J Infect 2011, 62:130-135

2. Naber CK: Staphylococcus aureus bacteremia: epidemiology, pathophysiology, and management strategies. Clin Infect Dis 2009, 48 Suppl 4:S231-S237

3. Lowy FD: Staphylococcus aureus infections. N Engl J Med 1998, 339:520-532

4. Steinberg JP, Clark CC, Hackman BO: Nosocomial and communityacquired Staphylococcus aureus bacteremias from 1980 to 1993 impact of intravascular devices and methicillin resistance. Clin Infect Dis 1996, 23:255-259

5. Fluit AC, Jones ME, Schmitz FJ, Acar J, Gupta R, Verhoef J: Antimicrobial susceptibility and frequency of occurrence of clinical blood isolates in Europe from the SENTRY antimicrobial surveillance program, 1997 and 1998. Clin Infect Dis 2000, 30:454-460

6. Furuno JP, Johnson JK, Schweizer ML, Uche A, Stine OC, Shurland SM, Forrest GN: Community-associated methicillin-resistant Staphylococcus aureus bacteremia and endocarditis among HIV patients: a cohort study. BMC Infect Dis 2011, 11:298

7. Rasmussen RV, Fowler VG Jr, Skov R, Bruun NE: Future challenges and treatment of Staphylococcus aureus bacteremia with emphasis on MRSA [Erratum appeared in Future Microbiol 2011,6:250]. Future Microbiol 2011, 6:43-56

8. Banchereau J, Steinman RM: Dendritic cells and the control of immunity. Nature 1991, 392:245-252 
9. Reis e Sousa C, Sher A, Kaye P: The role of dendritic cells in the induction and regulation of immunity to microbial infection. Curr Opin Immunol 1999, 11:392-399

10. Liu YJ: Dendritic cell subsets and lineages, and their functions in innate and adaptive immunity. Cell 2001, 106:259-262

11. Banchereau J, Briere F, Caux C, Davoust J, Lebecque S, Liu YJ, Pulendran B, Palucka K: Immunobiology of dendritic cells. Annu Rev Immunol 2000, 18:767-811

12. Scumpia PO, McAuliffe PF, O'Malley KA, Ungaro R, Uchida T, Matsumoto T, Remick DG, Clare-Salzler MJ, Moldawer LL, Efron PA: $\mathrm{CD}_{11 \mathrm{C}^{+}}$dendritic cells are required for survival in murine polymicrobial sepsis. J Immunol 2005, 175:3282-3286

13. Rahman S, Manuel SL, Khan ZK, Wigdahl B, Acheampong E, Tangy $F$, Jain P: Depletion of dendritic cells enhances susceptibility to cell-free infection of human T cell leukemia virus type 1 in CD11Cdiphtheria toxin receptor transgenic mice. J Immunol 2010, 184: 5553-5561

14. Loof TG, Rohde M, Chhatwal GS, Jung S, Medina E: The contribution of dendritic cells to host defenses against Streptococcus pyogenes $\mathrm{J}$ Infect Dis 2007, 196:1794-1803

15. Toliver-Kinsky TE, Cui W, Murphey ED, Lin C, Sherwood ER: Enhancement of dendritic cell production by fms-like tyrosine kinase-3 ligand increases the resistance of mice to a burn wound infection. J Immunol 2005, 174:404-410

16. Benjamim CF, Lundy SK, Lukacs NW, Hogaboam CM, Kunkel SL: Reversal of long-term sepsis-induced immunosuppression by dendritic cell. Blood 2004, 105:3588-3595

17. Jung S, Unutmaz D, Wong P, Sano G, De los Santos K, Sparwasser T, Wu S, Vuthoori S, Ko K, Zavala F, Pamer EG, Littman DR, Lang RA: In vivo depletion of $\mathrm{CD}_{11 \mathrm{C}^{+}}$dendritic cells abrogates priming of $\mathrm{CD}^{+}{ }^{+}$T cells by exogenous cell-associated antigens. Immunity 2002 , 17:211-220

18. Prajsnar TK, Cunliffe VT, Foster SJ, Renshaw SA: A novel vertebrate model of Staphylococcus aureus infection reveals phagocyte-dependent resistance of zebrafish to non-host specialized pathogens. Cell Microbiol 2008, 10:2312-2325

19. von Köckritz-Blickwede M, Rohde M, Oehmcke S, Miller LS, Cheung $A L$, Herwald $H$, Foster S, Medina $E$ : Immunological mechanisms underlying the genetic predisposition to severe Staphylococcus aureus infection in the mouse model. Am J Pathol 2008, 173:1657-1668

20. van Rijt LS, Jung S, Kleinjan A, Vos N, Willart M, Duez C, Hoogsteden $\mathrm{HC}$, Lambrecht BN: In vivo depletion of lung CD11c+ dendritic cells during allergen challenge abrogates the characteristic features of asthma. J Exp Med 2005, 201:981-991

21. Martin FJ, Parker D, Harfenist BS, Soong G, Prince A: Participation of CD11c + leukocytes in methicillin-resistant Staphylococcus aureus clearance from the lung. Infect Immun 2011, 79:1898-1904

22. Voyich JM, Braughton KR, Sturdevant DE, Whitney AR, Saïd-Salim B, Porcella SF, Long RD, Dorward DW, Gardner DJ, Kreiswirth BN, Musser JM, DeLeo FR: Insights into mechanisms used by Staphylococcus aureus to avoid destruction by human neutrophils. J Immunol 2005, 175:3907-3919
23. Gresham HD, Lowrance JH, Caver TE, Wilson BS, Cheung AL, Lindberg FP: Survival of Staphylococcus aureus inside neutrophils contributes to infection. J Immunol 2000, 164:3713-3722

24. Kubica M, Guzik K, Koziel J, Zarebski M, Richter W, Gajkowska B, Golda A, Maciag-Gudowska A, Brix K, Shaw L, Foster T, Potempa J: A potential new pathway for Staphylococcus aureus dissemination: the silent survival of S. aureus phagocytosed by human monocytederived macrophages. PLoS One 2008, 3:e1409

25. Das D, Bishayi B: Staphylococcal catalase protects intracellularly survived bacteria by destroying $\mathrm{H}_{2} \mathrm{O}_{2}$ produced by the murine peritoneal macrophages. Microb Pathog 2009, 47:57-67

26. Olivier AC, Lemaire S, Van Bambeke F, Tulkens PM, Oldfield E: Role of rsbU and staphyloxanthin in phagocytosis and intracellular growth of Staphylococcus aureus in human macrophages and endothelial cells. J Infect Dis 2009, 200:1367-1370

27. Liu GY, Essex A, Buchanan JT, Datta V, Hoffman HM, Bastian JF, Fierer J, Nizet: Staphylococcus aureus golden pigment impairs neutrophil killing and promotes virulence through its antioxidant activity. J Exp Med 2005, 202:209-215

28. Mölne L, Verdrengh M, Tarkowski A: Role of neutrophil leukocytes in cutaneous infection caused by Staphylococcus aureus. Infect Immun 2000, 68:6162-6167

29. Verdrengh M, Tarkowski A: Role of neutrophils in experimental septicemia and septic arthritis induced by Staphylococcus aureus. Infect Immun 1997, 65:2517-2521

30. Diep BA, Chan L, Tattevin P, Kajikawa O, Martin TR, Basuino L, Mai TT, Marbach $H$, Braughton KR, Whitney AR, Gardner DJ, Fan X, Tseng CW, Liu GY, Badiou C, Etienne J, Lina G, Matthay MA, DeLeo FR, Chambers HF: Polymorphonuclear leukocytes mediate Staphylococcus aureus Panton-Valentine leukocidin-induced lung inflammation and injury. Proc Natl Acad Sci USA 2010, 107:5587-5592

31. McLoughlin RM, Solinga RM, Rich J, Zaleski KJ, Cocchiaro JL, Risley A, Tzianabos AO, Lee JC: CD4+ T cells and CXC chemokines modulate the pathogenesis of Staphylococcus aureus wound infections. Proc Natl Acad Sci USA 2006, 103:10408-10413

32. Velasco E, Byington R, Martins CA, Schirmer M, Dias LM, Gonçalves VM: Comparative study of clinical characteristics of neutropenic and non-neutropenic adult cancer patients with bloodstream infections. Eur J Clin Microbiol Infect Dis 2006, 25:1-7

33. Venditti M, Falcone M, Micozzi A, Carfagna P, Taglietti F, Serra PF, Martino P: Staphylococcus aureus bacteremia in patients with hematologic malignancies: a retrospective case-control study. Haematologica 2003, 88:923-930

34. Thwaites GE, Gant V: Are bloodstream leukocytes Trojan Horses for the metastasis of Staphylococcus aureus? Nat Rev Microbiol 2011, 9:215-222

35. Hamza T, Barnett JB, Li B: Interleukin 12 a key immunoregulatory cytokine in infection applications. Int J Mol Sci 2010, 11:789-806

36. Haraguchi S, Day NK, Nelson RP Jr, Emmanuel P, Duplantier JE Christodoulou CS, Good RA: Interleukin 12 deficiency associated with recurrent infections. Proc Natl Acad Sci USA, 1998 95:1312513129

37. Hultgren $\mathrm{OH}$, Stenson M, Tarkowski A: Role of IL-12 in Staphylococcus aureus-triggered arthritis and sepsis. Arthritis Res 2001, 3:41-47 